\title{
An international review of the development and implementation of shared print storage
}

\author{
Paul Genoni \\ School of Media, Culture and Creative Arts \\ Curtin University \\ GPO Box U1987 \\ Perth, 6845
}

p.genoni@curtin.edu.au

\begin{abstract}
This article undertakes a review of the literature related to shared print storage and national repositories from 1980 - 2013. There is a separate overview of the relevant Australian literature. The coverage includes both relevant journal literature and major reports. In the process the article traces the developments in the theory and practice of shared print storage as the rapid emergence of digital content and services became apparent. This includes the increasingly broad-scale that has emerged in the planning for future print storage. Note is also taken of the paucity of research based evidence, and the discrepancies between the literature representing the interests of professional bodies with supra-regional responsibilities and the (sometimes) lack of activity or engagement by managers of individual collections.
\end{abstract}

Keywords: Shared storage; Print storage; Cooperative collection management; National repositories; Print repositories 


\title{
An international review of the development and implementation of shared print storage
}

\author{
Paul Genoni
}

\section{Introduction}

Shortage of storage space for print materials is not a new problem to be faced by libraries. Until recently collections have been intractably physical, and for many libraries they remain so to a surprising degree. As a result various strategies or "solutions" have been employed as libraries have struggled to find the necessary space. The purpose of this article is to review the literature relating to one such strategy, that of shared print storage. Shared or collaborative approaches to print storage have gathered increasing attention in recent years as libraries have looked for long-term solutions that reduce the cost required to house little used material.

Shared print storage comes in a diverse range of forms, models and scales but the argument put in favour of this approach is fairly consistent and straightforward and can be reduced to the following essentials:

- Storage in primary library sites is expensive and getting more expensive

- Space used for storage in primary library sites is increasingly in demand for other uses

- Off-site (remote), high density storage of low-use is considerably cheaper and in most cases will meet access (discovery and delivery) requirements

- Savings derived from off-site stores in terms of start-up costs, overheads and administration will be maximised if the store is owned and/or managed collaboratively

- Participating libraries can safely deduplicate collections and thereby obtain further savings, in the knowledge that a copy remains secure and accessible.

While to advocates of shared print storage the benefits can seem self-evident, the implementation of these types of stores has proceeded gradually. This is largely a result of the pressing need felt by most libraries to deal with digital priorities, and an associated reluctance to invest in parts of the collection (the so-called "legacy print" items) that are by definition in low demand and may-according to some predictions — be made fully redundant by advances in access to digital content.

This review of the literature on shared print storage is intended to guide interested readers to relevant sources, but also serves to indicate why a concept that can at times appear to be so obviously beneficial has not been wholeheartedly embraced. Such a review is also useful in 
pinpointing the major developments that have occurred and in identifying in prospect the likely future developments.

\section{Scope}

The review introduces in broadly chronological sequence a range of journal articles, conference presentations and reports that have reflected activity and/or influenced opinion and practice with regard to shared storage. A separate section of the paper is devoted to the Australian literature on the subject. For the most part I have chosen to foreground papers and reports that discuss the evolving practice of print storage in general rather than those that highlight particular examples, but at least some coverage of descriptions of significant examples of shared stores is necessary.

It should also be noted that there is considerable diversity with regard to the scale of shared print stores. The concept can include a small number of closely located libraries agreeing to find a mutually convenient building to accept their overflow storage; more geographically broadly-based libraries creating an independent repository that operates in order to encourage deduplication between member libraries; and nationally distributed networks involving no separate physical store but instead requiring participating libraries to assume particular responsibilities for last-copy retention. There are also hybrids or "mash-ups” of these models, displaying various models of management, membership, cost-distribution and service. All fall within the range of this literature review, as all are approaches to the shared storage of legacy print items. What is not included in the review, however, are items that simply deal with remote or high-density print storage, without regard to whether such stores are managed by a single library or represent some form of shared approach.

Another underlying issue in the literature of shared storage is the uncertain and evolving nature of the terminology. Just some of the conflicts that can arise are distinctions between "stores", "repositories” and "depositories"; between "shared storage”, “cooperative storage” and "collaborative storage"; and between "low-use collection”, "research collection" and "legacy print collection". It is not the purpose of this review to explore these issues of definition, although a number of the papers included do discuss the distinctions between these terms. In summarising the content of the various contributions to the literature I have generally chosen to use the terminology favoured by authors of each paper. I believe in this way the syntax of the original is honoured, and any discrepancies in the use of terms are not sufficiently significant that they will inhibit understanding.

$1980-2000$

Not surprisingly, there is no single starting point to the literature of shared storage. The early development of shared stores was a natural off-shoot from existing cooperative collection development arrangements enjoyed by libraries in close physical proximity. While cooperative collecting had initially focussed on the shared approach to selection in order to distribute costs and reduce unnecessary duplication, it was inevitably realised that a similar principle could be applied to retention and storage. The other important drivers were developments in remote storage, particularly after the implementation of Harvard 
University's high-density store in 1986 that introduced a storage method that has subsequently been used in many shared stores (Weeks and Chepesiuk, 2002); and-not surprisingly - the revolution in many aspects of library collections and services flowing from the ubiquity of digital content. In the final decades of the twentieth century the digital future seemed not only inevitable but increasingly transformative, and many research library managers began to ask questions about the future of print collections.

The implementation of shared stores is usually traced to the New England Deposit Library in the United States in the early 1940s. This service initially served seven and then later more libraries in the Boston area. This was followed by the Mid-West Inter-Library Center (later the Center for Research Libraries) in the early 1950s. These developments left little trace in the literature of the time, and in reviewing the literature of shared print storage it is a 1980 paper about developments in continental Europe that makes a serviceable starting point. Rolf Fuhlrott's (1980) article “Cooperative storage: lightening the burden of libraries” arose from a report prepared by the German Library Institute's Committee on Library Building, relating to future library buildings in that country. The paper remains relevant in that it outlined the arguments for and against the development of shared storage facilities, most of which remain common to later discussions. Fuhlrott was an advocate of shared storage, concluding that "experience ... has demonstrated that cooperative storage of materials on a regional or, in smaller countries, at national level promises the best way of coping with overcrowded libraries" (334). Fuhlrott also provided a brief history of the early development of shared storage facilities in the United States, and gave an account of the growing interest in national repositories in several European countries.

The prospect of storage at a national level was also exercising the International Federation of Library Associations' Universal Availability of Publications (UAP) program at this time. In 1982 the UAP (IFLA, 1982) published an international review of national repositories, the findings of which were summarised by Kennington and White (1982). As these documents indicate, however, the interest at the time was largely in developing passive ("dark”) repositories rather than active ("light") shared stores, and Kennington and White reported that "properly planned and integrated storage libraries remain ... a theory rather than a practice" (4). They also pointed to what would become an critical ongoing issue in the development of many shared print stores; that is, the long-term ownership of material, and the question of whether ownership should be retained by depositing libraries or relinquished to a separate body charged with managing the store.

The matter of active print storage sites was raised in Michael Buckland's 1990 article, "Little used duplicates, cooperative collection development, and storage”. Buckland sketched out the arguments in favour of removing duplicates from collections, noting that the problem with long term storage of duplicated research material is "very extensive" and that "most of the holdings of most large libraries are little-used duplicates” (41). He highlighted the various cost savings that are likely to result from sharing storage costs, and interestingly in terms of later discussions put a figure on "space saved” of “up to \$16 per volume” (45). Unfortunately Buckland gave no indication of exactly what this refers to (i.e. over what period of time?), or how or by whom it was calculated. Buckland also reviewed the arguments in favour of the 
retention of little-used duplicates, before concluding that cooperative storage is but one of several options libraries have in addressing space shortages. Buckland's advocacy of cooperative storage solutions is therefore tempered, but his article did at least foreground the issue of the need to reduce storage in primary library sites and raised issues regarding the impacts this might have on service. Interestingly Buckland concluded with a brief overview of developing technologies, and predicted that "trends in library technology seem to be heading in the direction of removing or reducing the constraints that make large local holdings of little-used duplicates important for effective library service” (50).

An important strand in the literature of shared storage has been the series of four conferences held in Kuopio, Finland. The first three of these were held under the generic title International Conference on Repository Libraries, in 1999, 2004 and 2009 (often referred to as Kuopio1, 2 and 3); and the fourth Kuopio conference was conducted as a satellite meeting to the IFLA Biennial Congress in 2012 with the title Global Policies, Imperatives and Solutions for the Efficient Collection Management and Access to Less Used Documents. While (as noted above) a "repository" is not the only model of a shared store, this series of conferences has emerged as an important international meeting point for proponents of not only broadly-based repositories but various forms of shared storage.

The Kuopio1 conference was organised under the auspices of the International Federation of Library Associations and coincided with the tenth anniversary of Finland's National Repository Library, a collection that can in many ways be seen as a model for other later developments, particularly throughout Europe. The proceedings of Kuopio1 collected over twenty papers edited by Pauline Connolly (1999) and were published as Solving Collection Problems Through Repository Strategies. The papers tended to focus on national repositories, many of them based on the collections and services of national libraries, and are a testimony to the amount of activity that was already taking place. The use of the shared repository model by academic libraries was featured in papers by Pascal Sanz (Director, Centre Technique du Livre) describing developments in France, and Donald B. Simpson (President, The Centre for Research Libraries) discussing the emerging trend amongst US academic libraries of extending established principles of cooperation with regard to collection development to include shared storage. Indications of the possibilities offered by more localised or specialised initiatives are present in several papers, including Emma Robinson's (1999) description of developments at the University of London; Beatrice Skold (1999) on the possibility of targeting special needs such as the blind and print handicapped; and Heikki Poroila (1999) on particular formats, in this case music materials.

The following year produced a paper by three authors from the Library of the University of Florida (Kisling, Haas and Cenzer, 2000) arguing in favour of "last copy depositories". Contextualised by the shift from "paper to pixels" it is argued that the development of regionally-based print stores is a natural development in the USA as libraries transition their cooperative collecting activities from acquisition to long-term management. While the focus is on journals and the inherent risks involved in allowing vendors to become the source of archived titles, the authors also envisage a future role for shared monograph storage. 


\section{1- 2005}

In 2001 Steve O’Connor, Andrew Wells and Mel Collier jointly-authored A Study of Collaborative Storage of Library Resources: Report for the Higher Education/ British Library Task Force. This report was published, with only minimal changes, the following year in Library Hi-Tech (O'Connor, Wells and Collier, 2002). While the report had a UK context and was framed in terms of recent initiatives and drivers towards enhanced collaboration in the UK higher education sector, it also took account of international developments and it provides, inter alia, an overview of collaborative storage developments elsewhere. The report is certainly supportive of the concept of collaborative storage in the UK, but stops short of making specific recommendations as to how this might be achieved. The authors point to the "lack of research into the extent of collection overlap or gap analysis" (267); the importance of individually owned collections and collection size to some libraries; and the capital cost associated with the "construction and sustainable operation" of repositories. The report also notes-without examining in depth-the uncertainty resulting from the emergence of long-term digital storage and the impact this might have on the need to retain print copies indefinitely.

It was also in 2001 that the USA-based Council on Library and Information Resources published a report on one of the most high-profile shared stores, the Massachusetts based Five-College Library Depository. This report was authored by Willis E. Bridegam (2001), the then Librarian of Amherst College, the library that had created the store that later formed the basis of the Five-College Depository. The Depository is described by Bridegam as a shared storage facility that was developed by libraries that had previously collaborated on other aspects of collection management. Bridegam's report provides a very through account of the key issues and decision-points (location of the facility; relinquishing ownership to the depository; environmental controls; access; staffing) in the development of the depository and its ongoing management. The report also included quite a deal of information regarding the financial arrangements for the depository, and although somewhat dated this remains interesting as it is at a level of detail that is rarely provided regarding the costs associated with particular shared stores.

The interest of the Council on Library and Information Resources in shared storage was further evidenced in the same year when (through its Task Force on the Artifact in Library Collections) it sponsored a major report, The Evidence in Hand. This report was based on the need to consider long term preservation, and included a wide ranging survey of the changing place of the printed artifact as various factors impacted upon the traditional approach to the long term, duplicated retention of print items in the nation's research collections. One recommendation was that members of the research community should "Advocate for the development of regional repositories of artifactual collections that reduce duplication of effort, create economies of scale, and ensure that the greatest number of unique or scarce priority items are preserved and made accessible to researchers” (x). The report suggests that these repositories might be organised by using principles of chronology, discipline or geography. The report also recommended a national level "repository of record for American imprints”. 
The Evidence in Hand report had a sequel in 2003 with Bernard F. Reilly's Developing Print Repositories: Models for Shared Preservation and Access. This report was once again commissioned by the Council on Library and Information Resources in order to obtain a better understanding of the forms of shared print repositories that were emerging in the USA. Reilly, President of the Center for Research Libraries, identified a number of "regional repositories" that he groups according to three types; the state model (funding provided by "the respective state university systems" (20)); the consortium model (funding derived from consortium members and sometime operating across state boundaries); and the proprietary model (a repository funded by a single institution to serve constituent libraries). For each of these models Reilly examined the variety of organisational, management, service and funding arrangements that exist, creating an impression of a quite complex array of options. In his search for print repository models Reilly also describes the emergence of USA based "supraregional and national-level repositories", and international examples in the form of the National Repository Library of Finland and Australia’s CARM Centre.

In discussing these various models Reilly addressed the "important differences between common management of collections and shared ownership" (16). His conclusion was that the "issue of ownership is something of a red herring" (17), and that it is through cooperative management according to an agreed set of policies and service procedures that shared stores achieve the all-important economies.

In looking ahead Reilly envisaged that major USA research libraries could exist in a network of regional and national-level repositories "that enables strategic management of the important primary resources for scholarship" (40), while warning that the "appeal of cooperative repositories is often less compelling for library directors and staff than for university and state administrators" (39). Another section of the report (34-39) discussed the various factors that enable and promote successful cooperation for storage and other collection management activities.

At a similar point in time the UK was also looking to find the right scale and model under which to proceed towards a vision of distributed print storage, but the inclination was towards a national scheme supporting agreed retention rather than a network of regional and/or local stores. A major development came with the CHEMS Consulting (2005) report Optimising Storage and Access in UK Research Libraries prepared for the Consortium of Research Libraries (CURL) and the British Library in 2005. The report argued for the necessity of some form of shared storage future based on the ongoing shortage of capital funds to increase library storage space and the emergence of digital storage and transfer of content. The report conceded, however, that important data regarding collection overlap remained poor and that there was "no available evidence of the amount of de-duplication and space saving that could be achieved" (15).

In gathering background data for the report some 42 research libraries responded to a questionnaire regarding their current storage situation and future plans. The evidence from this survey recorded widespread concern regarding future storage, although once again there was a shortage of reliable data available regarding either the costs associated with current 
storage practices or the space required for future storage. The report reported that despite a space crisis most libraries were "still very cautious" (16) with regard to their disposal and storage practices.

The report also surveyed existing national and international (USA and Australian) practice with regard to shared storage, before culminating in five options for future print storage of what was dubbed-without a precise definition - the National Research Reserve or NRR (31). Three of the options envisaged different scenarios for cooperation and collaboration in a national network of stores; a fourth option was a future based on the collections of the British Library "with some additions from research libraries" (27); and a fifth was basically the status quo with the "responsibility on university librarians for finding answers to their own storage problems" (27). After consideration of each option the report supported the adoption of option 4, referred to as the "British Library-Based Scheme". The report concluded by making suggestions regarding the practical aspects of the preferred option, including management, funding, and impacts on stakeholders, and in the process produced some figures related to the projected savings in terms of linear metres of shelving; national storage costs; and future capital expenditure.

Papers continued to appear during this period describing the implementation of repositories on both a national and regional scale. The former included an update by Pentti Vattulainen (2004) on Finland's National Repository Library (NRL), although he also provided briefer accounts of similar developments in Norway, Estonia, France and Scotland. Vattulainen concluded that the NRL "creates savings in total storage costs on a national level”, through "deduplication, joint management, and specialized storage” (48). Scott Seaman (2005) produced an account of a regional shared high-density storage facility, the Preservation and Access Center for Colorado Academic libraries (PASCAL), serving four public and privately funded universities with 23 libraries. PASCAL was designed as a store for single copies of low-use material with libraries encouraged to deduplicate local collections. Seaman reported that "the issue of most concern to librarians was ownership of stored materials" (23) and volume counts for participating libraries, and therefore "single copy" was defined as one copy for each university for monographs, and a single copy only for journals. Libraries therefore retained ownership of material, but items are shared to the extent that they are available for direct loan by registered users of the member universities.

It was also in 2005 that the proceedings from the Kuopio2 conference (held in August 2004) were published as a special issue of Library Management (Volume 26, Nos 1/2). This proved to be a significant gathering of contributions from some of the leading advocates of shared storage, including Steve O’Connor (then, as now, editor of Library Management); Bernard F. Reilly; Pentti Vattulainen; Peter Johan Lor, and Lizanne Payne. There were some fourteen papers included, and as with the Kuopio1 proceedings they attested to the international interest in national repositories, with contributions covering developments in a number of European countries, the USA, Africa and Australia.

Several of the papers described recent developments in shared repositories for academic libraries. These included O'Connor's (2005) account of the CARM Centre in Australia; 
Catherine Nicholson's (2005) description of the Cooperative Academic Store for Scotland (CASS); and Jarmo Saarti (2005) providing another account of Finland's National Repository Library. Not all developments were fully positive, however, with Klaus Kempf (2005) reporting some less successful moves towards shared academic library storage in Germany.

The USA was represented in the Kuopio2 proceedings by a paper by Bernard F. Reilly (2005) outlining the commitment by the Center for Research Libraries to play a lead role in ensuring the future accessibility of the nation's print corpus through the development of a network of shared stores; and Lizanne Payne's (2005) paper on the "changing models of library storage in the USA", in which she described the increasing reliance on off-site storage, in both single-institution and shared facilities. With regard to the latter Payne was careful to distinguish between depositories (in which individual libraries retain ownership of stored items) from repositories (in which ownership is transferred to the repository). She identified that the only shared storage facility that was operating was a "true repository" was the example of the Five Colleges Inc., in Massachusetts (as noted above this service had previously been described by Bridegam, 2001).

\section{6-2013}

In the following year, 2006, David Kohl (University Librarian, Emeritus, University of Cincinnati) and Tom Sanville (Executive Director of OhioLINK) co-authored an overview of developments in consortia in the US, pinpointing "storing books in a cost effective manner" (398) as one of the emerging priorities. As with other discussions of the issue they made general but largely unsupported claims regarding the savings that might eventuate, and concluded that while "more detailed studies would further and more definitely identify the exact size of the improvement in the cost-benefit ratio, the present evidence is already compelling” (400).

2006 also saw a report from the Canadian Association of Research Libraries Committee on Scholarly Communication (2006) describing the major repositories serving the academic library community in that country. Of the twelve repositories described in the survey, four represented some form of consortium. This report which was compiled in order to "spur further discussion of storage solutions for 'last print copies"” (3) did not, however, include any detailed discussion or recommendations regarding the future of print storage for Canadian university libraries.

Canada was also (in part) the subject of the next significant report on the subject of shared storage, Lizanne Payne's (2007) Library Storage Facilities and the Future of Print Collections in North America. Payne was at the time Executive Director of the Washington Research Library Consortium, and the report was commissioned by the OCLC Programs and Research office. Payne's report followed from her 2005 paper in that she again built her discussion around the mainstreaming of high-density storage facilities (both on-site and remote) in North America, including Canada. She estimated that at the time some $7 \%$ of the holdings of academic libraries in North America were in high-density facilities. Payne's examination of the impact of digital content and technologies on print storage extended to the 
emerging "mass digitization" programs such as Google books, and the advent of "small-scale book scanning" (20), as a result of which she concluded that "academic institutions are questioning whether their already low-use print collections will be made obsolete" (22). Payne's solution was to suggest the implementation of a "distributed print repository network" (25) which she described as "a broader, system-wide approach to maintaining print collections across institutional boundaries" (29). She did not move far beyond the previous work of Reilly in examining the details of exactly how such networks might function, but did speculate that they could be implemented "on a regional, national or even global scale" (26).

2007 also saw a rare contribution to the literature from an Asian country, with Hee-Yoon Yoon and Sun-Kyung Oh's account of the situation in South Korea. They described the shortage of storage space being experienced by the country's National Library and public libraries, and proposed a model for a "national collaborative repository" (277) based on a series of "hubs" (or "regional data preservation centers" (277)) and serving all types of libraries. The question was left open as to whether these regional hubs should be managed independently or under a yet-to-be-established national body.

In the UK a national collaborative storage scheme (if not body) finally emerged in 2007. The suggestion in the CHEMS Consulting (2005) report for a "National Research Reserve" based on the holdings of the British Library with the support of a group of academic libraries was born as the United Kingdom Research Reserve (UKRR) with funding provided by the Higher Education Funding Council for England. The UKRR has focused on reducing duplication of journals while ensuring the retention of at least three copies within the participating libraries. While not a "shared store" in the proper sense, it is nonetheless a high-profile example of collaborative print storage on a national level. From soon after its inception the UKRR has been the focus of a series of papers explaining and assessing its operation at either a systemwide or institutional level. These include Shorley (2008); Wright and Crawford (2008); Sharp (2009); Boyle and Brown (2010); and Yang (2013).

Steve O’Connor and Cathie Jilovsky (2008) summarised some of the major international developments of the previous decade under the title "Approaches to the storage of low use and last copy research materials". While the purpose of the paper was to advocate for a national approach to print storage in Australia, in the process they summarised both the recent achievements in terms of shared print storage plus the frustrations felt by advocates of the approach who believed that more could be done. In particular they pointed to the dangers inherent in the "totally captivating and comprehensive" (123) effect of digital technologies that forestalled a properly considered and planned approach to print management. On a related matter they also noted that while the impact of mass-digitisation (Google Books) and open access were obviously substantial, the "economics of the retention of print in a digital age remains uninvestigated" (124).

In 2010 Cathy Maskell, Jennifer Soutter and Kristina Oldenburg reported the results of a survey of Canadian library directors' views of collaborative print repositories. Those surveyed were all members of the Ontario Council of University Libraries (OCUL), a consortium of 20 university libraries serving the Canadian province. The consortium manages 
a digital repository, Scholars Portal, but no print repository service (although several member libraries maintain independent print storage facilities). Interviews therefore explored the directors' views regarding the need to support the digital service with a print repository. The interviews revealed a lack of consensus regarding shared print storage. There was agreement regarding the importance of cooperation and the need to constrain costs, but less certainty as to exactly what benefits shared storage could deliver, or what model would best suit the needs of the participating libraries. Some of the unresolved matters concerned the value of a regional response to storage or whether this "should more appropriately be done on a national or even international level” (247). One matter that did produce agreement concerned the need for a dual digital-print strategy, and that "any OCUL print repository strategy would be directly informed by ongoing developments of Scholars Portal specifically, and more generally, by the broad shift to digital scholarly communications” (246).

The balance between digital and print storage futures was also integral to an important piece of research published in 2010, which while not directly addressing shared storage did "answer" a question that had been asked on numerous occasions by previous commentators: that is, the comparative cost of keeping a book on an open stack as compared to a high density facility. Courant and Nielsen (2010) concluded that the annual cost of the former was \$4.26 (in 2009 US\$) as compared to \$0.86 for the latter. While Courant and Nielsen were most interested in arguing in favour of the long term savings associated with digital storage, they also noted that in a largely digital future "libraries could share their print storage, keeping only several copies nationally or regionally, rather than duplicating substantial swaths of their collections", and that based on their cost calculations, "the savings from sharing of this kind could be substantial” (99).

The USA generated two important reports in 2011. The first of these was Sharing a Federal Print Repository, prepared by the Federal Research Division of the Library of Congress. This report considered the preferred print-storage option for Federal libraries including the Library of Congress, and asked whether they should "enter into a cooperative agreement to share an environmentally controlled, off-site storage facility, or ... each establish their own off-site storage annex?” (44). In responding to this question the report compiled data including a survey of different models of off-site storage (both shared and single library) operating in the USA; and responses to a survey of federal librarians as to their current storage circumstances and future plans. In a sign of the rapidly developing digital context the report also gave considerable space to the emerging digital repositories (notably the Internet Archive and the Hathi Trust), and while acknowledging the impact of these digital sources on decisions with regard to print it also warned of the problems associated with over-reliance on digital content. In the end the report did not recommend a single way forward but rather listed a series of "issues to be considered" should the Federal libraries choose to opt for a print storage consortium. These include the need for an agreed "overall mission" including whether the intention was to create "a shared storage facility, or a shared archive" (44); the forms of governance that would be required; and the preferred form of intellectual access via a “common cataloguing tool” (44). 
The second major report from 2011, once more produced under the auspices of the OCLC Research program (following on from Payne’s 2007 report), was Constance Malpas's CloudSourcing Research Collections: Managing Print in the Mass-digitized Environment. This report is further testimony to the manner in which developments in digital technology are shifting the parameters for the implementation of shared storage solutions for legacy print materials. Whereas consideration of mass-digitization had been peripheral to Payne's 2007 report, it is now featured as a pivotal development that must be integrated into future planning for print storage. The particular "mass-digitization" program addressed by Malpas is the Hathi Trust, and the focus of much of the report is on assessing the current and projected duplication of content between the Hathi Trust database and the corpus of print material in US academic libraries. The report acknowledges that in future usage of research materials will increasingly be provided from a mass-digitization source, but argues that this does not invalidate the need for securely stored and properly preserved print copies on a regional basis. Indeed Malpas argues that mass-digitization will enhance the need for shared storage as it will accelerate "the transfer of mass-digitized titles to print preservation repositories" (65). In other words, it is projected that an increasingly small percentage of a library's print acquisitions will be retained medium- or long-term in a primary storage site and that agreeable arrangements therefore need to be found for their off-site, high-density retention. Malpas concludes that the future of high-density storage is in the creation of "shared and cooperatively managed assets" that "leverage the collective library investment in Hathi". The future according to Malpas is an integrated digital and print archive that is built around “mass” in both cases.

In recent years the Center for Research Libraries has led several professional meetings investigating the future of shared print storage in the US, with a particular focus on moving beyond stores operating at the state or regional level and towards some form of national system. The discussions of a meeting convened in Chicago in July 2009 were reported by Kieft and Reilly (2009), who recorded that "models for and pieces of a comprehensive collective approach to print library collections exist around the country"; and that "The next step will be to reach consensus on the information, tools, standards, services, business arrangements and policies that are needed to create and sustain a national program of print preservation” (107). It was envisaged that this program would have a place for academic, independent and public libraries.

Kieft joined with Lizanne Payne in reporting (Kieft and Payne, 2010) the results of a followup workshop held in October 2010 with the title "Developing a North-American Strategy to Preserve and Manage Print Collections of Monograph". This meeting brought together representatives from a wide range of leading professional groups in an attempt to broaden the base of cooperation into something akin to a national program aimed at "libraries of various sizes, with different traditions and missions and in various kinds of partnerships reducing their print footprint and relying on a relatively small number of (stored) print copies” (230). As reported by Kieft and Payne the workshop discussions also identified an extensive program of research that was required in order to support future decision-making and activity with regard to developing a national print retention strategy. 
Kieft and Payne also contributed to a special issue (Volume 37, Nos 3 \& 4) of Collection Management devoted to shared print repositories published in late 2012. The twelve articles in this special issue reported in the main on developments within existing USA local and regional repositories, but also included contributions from Canada (Bird and Ashoughian, 2012) and Australia (Wright, Jilovsky and Anderson, 2012). Articles that dealt with more general matters related to shared print storage included a contribution by Susan Clement (2012) tracing the shift in collection collaboration from acquisitions to storage and the emergence of more geographically distributed regional stores; and Samuel Demas and Mary E. Miller on the need for libraries (and networks of libraries) to update their collection management policy and planning documents as they "reenvision collection management in the context of local, regional, and national priorities" (168). In their article Kieft and Payne (2012) considered the "explosion of shared print initiatives among academic libraries in North America and around the world" (142), and envisaged a future in which "ad hoc shared print initiatives are likely transformed by increased scale, scope, connectivity, and costsharing” (143). With this in mind they sketched out a vision of shared print storage for 2020 based on "mega-regional" storage; broader content as existing shared stores moved from journals to monographs; and more developed systems of cost-sharing.

The possibility of scaling US print repositories on a mega-regional basis was also the focus of a 2012 report, Print Management at "Mega-scale”: A Regional Perspective on Print Book Collections in North America (Lavoie, Malpas and Shipengrover, 2012). This report was produced once more under the auspices of OCLC Research. The authors drew upon recent research and modelling that has identified twelve North-American mega-regions, three of which cross international borders (between the USA and Canada). A mega-region is defined as "a geographical concentration of population and economic activity, generally subsuming multiple metropolitan areas and their surrounding hinterlands, and linked together through a complex connective tissue of economic interdependency, shared infrastructure, a common cultural history, and other mutual interests” (15). The report used data from OCLC's WorldCat to model a possible future for print storage that is scaled around mega-regions while drawing upon the existing collaborative infrastructure. The results are somewhat inconclusive, although the report suggests that the exact nature of repository services is likely to differ between mega-regions depending on existing collaborations, and there is also concern for the capacity to easily include material that falls outside the mega-regional clusters. The authors also stress the importance of broadening the base of collaboration beyond libraries with a shared focus (eg academic libraries), suggesting that "unless multitype partnerships are established, it will be difficult - if not impossible - to ensure that the remarkable breadth and diversity of the North American print book collection is preserved for future citizens and scholars" (57).

Finally, another special issue of a journal on shared print storage is due in 2013, with Library Management again set to publish the proceedings of a Kuopio conference (Kuopio4 from August 2012) in Volume 34, Nos. 4/5. Several papers include updated reports regarding existing repositories in the United Kingdom (Yang, 2013), Europe (Saarti and Vattulainen, 2013), the United States (Reilly, 2013) and Australia (Jilovsky, 2013). A newer repository on 
a national scale that is featured is the description by Helen Renwick, Librarian of the University of Auckland, of the recently implemented CONZUL (Council of New Zealand University Librarians) store. Renwick discusses the long gestation of the service (from 2000), and the key decisions that have resulted in the ceding of ownership of deposited material to Universities New Zealand; the outsourcing of a distributed network of storage sites to commercial providers; and an initial emphasis on journals with monographs to be included at a later stage.

\section{Australia}

The first major Australian shared storage facility was the Joint Library Store developed by the University of Adelaide and Flinders University in 1984. The store now operates under the title of Universities' Research Repository South Australia (URRSA), and the membership has been expanded to include the University of South Australia. An account of the early development and operation of this facility was provided by Baudinette (1999).

The major subsequent development has been the CARM Centre located in Bundoora, Melbourne. The CARM Centre is managed by CAVAL, a not for profit company owned by the eleven member universities. As noted in the review of the international literature the CARM Centre has often been used as a benchmark for good practice with regard to a shared print store. The first description of the CARM Centre and its collection and services was provided by the then CEO of CAVAL, Steve O’Connor (2004). O’Connor grounded his description of the CARM Centre in the declining capacity of Australian university libraries to collect comprehensively and therefore their increased need to collaborate on a range of collection management issues. The CARM Centre is described as a repository of low-use research material with ownership relinquished by participating libraries. O’Connor (2005) provided another account of the CARM Centre in the following year, on this occasion focusing the discussion on the economic benefits of repository libraries. In doing so he stressed that a problem in creating a sound economic footing for the repository was that nonmember libraries could derive an economic benefit by discarding items in the CARM Centre knowing that the item would be permanently available to the Australian research community.

A substantial extension to the CARM Centre (CARM2) was opened in December 2010, and this development has been described in a paper by Jeanette Wright (who followed O'Connor as the CEO of CAVAL), Cathie Jilovsky and Craig Anderson (2012). An interesting element of this paper is the description of the business case for the building of this extension in circumstances where "there was little appetite among government agencies for funding the extension" (276). As a result the business case for the building of CARM2 saw a break from the repository (shared ownership of the collection) model, to one based on "provision for separately leased or licensed space within the facility, to be managed by CAVAL but permitting each library to retain ownership and control of its off-site collections” (278). Cathie Jilovsky (2013) presented a further overview of the CARM2 development for the Kuopio4 Conference that will appear in the forthcoming special issue of Library Management. 
There have been intermittent proposals for other Australian shared print stores, primarily intended to serve academic libraries and therefore discussed within the Council of Australian University Librarians (CAUL) and its membership, and dating back several decades. Some of these proposals have been for local or regional stores, and some for national facilities (either centralised or networked). The most substantial document resulting from these discussions was the National Collaborative Library Storage Strategy (CAUL 2004), produced at a time when support for the concept within CAUL appeared to be waning. An account of the history of CAUL considerations of shared print storage was the subject of an article by Paul Genoni (2007). This paper also suggested a way forward for a national print research repository, which included the instigation of a new research library-based body with a broader remit (i.e. extending beyond university libraries) than CAUL and charged with "resolving the key management and policy issues associated with a national repository" (95).

Genoni has subsequently undertaken and reported research intended to assess the potential benefits of implementing a national print repository in Australia. The first of these papers (Genoni 2008) reported on the results of a survey of Australian university libraries that asked them to report on aspects of their current and possible future activity with regard to print storage, including the prospects for shared storage. The paper concluded with a claim that the long-term optimisation of print storage "may only be achieved by a fully coordinated and implemented national store" (39), while also noting the ongoing problems with regard to research focused libraries ceding ownership of stored items.

This preceded a series of papers by Genoni undertaken in conjunction with CAVAL staff (Jilovsky and Genoni, 2008; Genoni and Varga, 2009; Genoni and Wright, 2010; Genoni and Wright, 2011) and based on measuring the overlap between various Australian research library collections (including the existing CARM store) with a view to assessing the potential for placing increased reliance on a shared print repository. The broad purpose of this research was to determine the potential for space savings by both Victorian and other research libraries if duplicated items could be withdrawn, and to gather additional data related to a possible national academic/ research store.

A further element to this research was a survey (email based interview) conducted with six Australian and one New Zealand based university librarian (Genoni, 2012) on the storage of legacy print collections. Separate sections of the survey asked for responses based on firstly, current institutional practice; and secondly, the respondents' personal views. The matters canvassed included shared storage; the need for national autonomy in print collections; the impact of mass-digitisation; and collaboration between different library sectors with regard to print storage. It was concluded that the respondents had "a strong preference for joint or collaborative storage but that the issue is far from straightforward” (28). Complicating factors included the need or desire to retain ownership for reporting purposes, and uncertainty regarding the impact of mass-digitisation programs. The distinction in responses from librarians representing research intensive universities and those with a more teaching and learning focused mission was also reported.

\section{Conclusion}


The accumulated literature of shared print storage demonstrates an odd mixture of stability and volatility. The stable element has been provided by the arguments put in favour of the concept, which are consistently based on the potential to deliver cost savings with regard to long term print storage. This is claimed to be true whether the sharing is done on the basis of a small number of libraries located within a small geographic area; or on a diverse megaregional basis that might operate up to a national level. It is also said to be the case-although the magnitude of savings will vary - if the sharing is done on the basis of a single, highdensity store that is centrally located, or a distributed network of stores, that might indeed be no more than open access shelves, with a single copy being the basis of deduplication by other participating libraries.

What has been volatile has been the need to take account of developments in digital technologies that have created an unstable infrastructure environment. On one hand the increased availability of low-cost digital storage, and rapid, high-quality digital delivery has made remote print storage increasingly acceptable from a service point-of-view. On the other hand the prospect of ongoing developments in mass-digitisation has left some library managers questioning whether it is necessary to invest further in local print storage. It is this dual impact of digital storage and delivery that has also driven a shift in the approach to scaling shared print storage. Whereas the literature has long covered both broad-scale initiatives in the form of national repositories, plus the solutions implemented by local or regional collaboration, there has been a discernible shift towards seeking solutions based around mega-regional (often national) approaches. The United States has been a yardstick in this regard. Whereas the concept of national approaches always seemed more feasible in the context of the smaller European countries, the United States came to the idea somewhat later and on the back of number of previously implemented regional stores. Such is the emergence of capability to massively upscale print storage in the quest to maximise cost savings that it is hardly surprising that interest is now moving to the potential for international solutions. Irrespective of the scale, however, similar decisions need to be made, and the literature is heavy with contributions that deliberate on the key choices between centralised or distributed storage: retained or ceded ownership; “dark or "light” repositories; journals or monographs.

It must also be noted that many of the arguments in favour of print storage are mounted on the basis of what appears to be obvious to authors. Genuine research based opinion is difficult to come by. This is not surprising given that there are some inherent difficulties in assessing some of the key variables, and even such fundamental data as the cost of storing a book (either in high-density remote storage or on open shelving) has been difficult to determine with certainty. The potential for system wide savings flowing from the development of one or other form of shared storage is also extremely difficult to quantify across a network of libraries. In some respects, however, it should be noted that the capacity to source relevant data has improved, particularly due to the development of OCLC's WorldCat database and its supporting software services that have substantially improved data collection with regard to collection overlap and uniqueness, and this has been reflected in recent research.

For some library managers, however, the quantity and quality of the data may be irrelevant. Sharing or collaboration inevitably involves some shifting of costs, and the literature reveals 
a caution (or even suspicion) with regard to the impact this might have on particular libraries. Network wide savings are fine, but individual library managers are likely to continue to make decisions based on the interests of their individual service. It is a characteristic of the literature of shared print storage that it reveals the tension between those with an eye to the network costs and service delivery, and those charged with overseeing local budgets and decision making.

And it could also be argued that the literature itself may indicate that the relevant data will never be sufficient to drive decision making for individual libraries. In the current technological environment print storage solutions (be they shared or otherwise) require astute professional judgement, a leap of faith, and considerable boldness. Some libraries (and librarians) remain reluctant to act without either the benefit of hindsight or absolute confidence in the future.

\section{REFERENCES}

Baudinette, Kaye L. (1999) "The Flinders University and University of Adelaide Joint Library Store.” In Adelaide 98, Pathways to Knowledge: Australian Library and Information Association 5th Biennial Conference and Exhibition, 25-28 October 1998, Adelaide Convention Centre, Canberra: Australian Library and Information Association.

Bird, Gwen, and Gohar Ashoughian. 2012. "All Together Now: Planning for Shared Print Archiving at Canada's Western Universities.” Collection Management 37(3/4): 260-270.

Boyle, Frances, and Chris Brown. 2010. "The UK Research Reserve (UKRR): Machinations, Mayhem and Magic.” Interlending \& Document Supply 38(3): 140-146.

Bridegam, Willis E. 2001. A Collaborative Approach to Collection Storage: The FiveCollege Library Depository. Washington: Council on Library and Information Resources.

Buckland, Michael K. 1990. "Little Used Duplicates, Cooperative Collection Development, and Storage.” Collection Management 13(4): 39-52.

Canadian Association of Research Libraries. 2006. Print Repository Initiatives at Canadian University Libraries: An Overview. Ottawa: CARL.

CHEMS Consulting. 2005. Optimising Storage and Access in UK Research Libraries: A Study for CURL and the British Library. CHEMS Consulting.

Clement, Susanne K. 2012. "From Collaborative Purchasing Towards Collaborative Discarding: The Evolution of the Shared Print Repository.” Collection Management 37(3-4): 153-167.

Connolly, Pauline, ed. 1999. Solving Collection Problems Through Repository Strategies: Proceedings of an International Conference held in Kuopio, Finland, 9-11 May 1999. Boston Spa: International Federation of Library Associations. 
Council of Australian University Librarians. 2004. National Collaborative Library Storage Strategy. Accessed Jan 112012.

www.caul.edu.au/content/upload/files/caul-doc/caul20041store.doc

Council on Library and Information Resources. 2001. Task Force on the Artifact in Library Collections. The Evidence in Hand: Report of the Task Force on the Artifact in Library Collections. Washington: CLIR.

Courant, Paul N. and Matthew "Buzzy” Nielsen (2010). “On the Cost of Keeping a Book.” In The Idea of Order: Transforming Research Collections for the Twenty-first Century, 81-105. Washington D.C.: Council on Libraries and Information Resources. Accessed January 4, 2013. http://www.clir.org/pubs/reports/pub147/reports/pub147/pub147.pdf

Fuhlrott, Rolf. 1980. “Cooperative Storage: Lightening the Burden of Libraries.” Libri 30(4): 321-337.

Genoni, Paul. 2007. "Towards a National Print Repository for Australia: Where from and Where to?” Australian Academic and Research Libraries 38(2): 84-98.

Genoni, Paul. 2008. Current and Future Print Storage for Australian Academic Libraries: Results of a Survey. Library Collections, Acquisitions \& Technical Services 32(1): 31-41.

Genoni, Paul. 2012. "Storage of Legacy Print Collections: The Views of Australasian University Librarians.” Collection Management 27(1): 23-46.

Genoni, Paul, and Eva Varga. 2009. “Assessing the Potential for a National Print Repository: Results of an Australian Overlap Study.” College \& Research Libraries , 70(6): 555-567.

Genoni, Paul, and Jeanette Wright. 2010. Assessing the Collective Wealth of Australian Research Libraries: Measuring Overlap Using WorldCat Collection Analysis.” Australian Library Journal 59(4): 197-207.

Genoni, Paul, and Jeanette Wright. 2011. Australia's National Research Collection: Overlap, Uniqueness and Distribution. Australian Academic and Research Libraries 42(3): 162-178.

International Federation of Library Associations. 1982. National Repository Plans and Programmes: A Comparative Study of Existing Plans and Possible Models. Wetherby: IFLA International Office for UAP.

Jilovsky, Cathie. 2013 forthcoming. "The CARM2 Print Repository: From Planning to Operations.” Library Management 34(4/5).

Jilovsky, Cathie, and Paul Genoni. 2008. "Changing library spaces: finding a place for print.” Libraries/Changing Spaces, Virtual Places: VALA, 14th Biennial Conference. Melbourne: Victorian Association for Library Automation. Accessed Jan 112012. http://ebookbrowse.com/49-jilovsky-final-pdf-d38278802 
Kennington, Don, and Brenda White. 1982. "National Repository Plans and Programmes.” Interlending Review 10(1): 3-7.

Kieft, Robert H., and Bernard F. Reilly. 2009. "Regional and National Cooperation on Legacy Print Collections.” Collaborative Librarianship 1(3): 106-08.

Kieft, Robert H., and Lizanne Payne. 2010. "A Nation-Wide Planning Framework for LargeScale Collaboration on Legacy Print Monograph Collections.” Collaborative Librarianship 2(4): 229-33.

Kieft, Robert H., and Lizanne Payne. 2012. "Collective Collection: Collective Action." Collection Management 37(3-4): 137-152.

Kisling, Vernon N., Stephanie Cornell Haas, and Pamela S. Cenzer. 2000. "Last Copy Depository: Cooperative Collection Management Centers in the Electronic Age." Collection Management 24(1/2): 87-92.

Kohl, David F., and Tom Sanville. 2006. "More Bang for the Buck: Increasing the Effectiveness of Library Expenditures through Cooperation.” Library Trends 54(3): 394-410.

Lavoie, Brian, Constance Malpas and J. D. Shipengrover. 2012. Print Management at "Mega-scale": A Regional Perspective on Print Book Collections in North America. Dublin, Ohio: OCLC Research. Accessed Jan 4, 2013.

http://www.oclc.org/research/publications/library/2012/2012-05.pdf.

Library of Congress. 2011. Sharing a Federal Print Repository: Issues and Opportunities. A Report Prepared by the Federal Research Division, Library of Congress Under an Agreement with the Federal Library and Information Committee (FLICC), Library of Congress. Washington: Federal Research Division Library of Congress.

Malpas, Constance. 2011. Cloud-sourcing Research Collections: Managing Print in the Mass-digitized Library Environment. Dublin, Ohio: OCLC.

Maskell, Cathy, Jennifer Soutter and Kristina Oldenburg. 2010. "Collaborative Print Repositories: A Case Study of Library Directors' Views.” Journal of Academic Librarianship 36(3): 242-249.

Nicholson, Catherine M. 2005. "CASS: A Cooperative Academic Store for Scotland.” Library Management 26(1/2): 32-41.

O’Connor, Steve. 2004. “Collaborative Strategies for Low-use Research Materials.” Library Collections, Acquisitions \& Technical Services. 28: 51-57.

O’Connor, Steve. 2005. "The Economics of Repository Libraries in the Context of the Future Conventional Libraries.” Library Management 26(1/2): 18-25. 
O’Connor, Steve, and Cathie Jilovsky. 2008. "Approaches to the Storage of Low Use and Last Copy Research Materials.” Library Collections, Acquisitions \& Technical Services 32(3/4): 121-126.

O’Connor, Steve, Andrew Wells, and Mel Collier. 2001. A Study of Collaborative Storage of Library Resources: Report for the Higher Education/ British Library Task Force. Bundoora: CAVAL Limited.

O’Connor, Steve, Andrew Wells and Mel Collier. 2002. “A Study of Collaborative Storage of Library Resources.” Library Hi-Tech 20(3): 258-69.

Payne, Lizanne. 2005. "Depositories and Repositories: Changing Models of Library Storage in the USA.” Library Management 26(1/2): 10-17.

Payne, Lizanne. 2007. Library Storage Facilities and the Future of Print Collections in North America. Dublin, Ohio: OCLC.

Poroila, Heikki. 1999. 'Repository Libraries and Music Material.” In Solving Collection Problems Through Repository Strategies: Proceedings of an International Conference held in Kuopio, Finland, 9-11 May 1999: 177-178. Boston Spa: International Federation of Library Associations. Boston Spa: International Federation of Library Associations.

Reilly, Bernard F. 2003. Developing Print Repositories: Models for Shared Preservation and Access. Washington: Council on Library and Information Resources. Accessed January 8, 2013. www.clir.org/pubs/reports/pub117/pub117.pdf

Reilly, Bernard F. 2005. "Preserving American Print Resources." Library Management 26(1/2): 102-105.

Reilly, Bernard F. 2013 forthcoming. 'The Future of Cooperative Collections and National Repositories: A Case Study of the Center for Research Libraries.' Library Management 34(4/5).

Renwick, Helen. 2013 forthcoming. 'Preserving Print Collections: The New Zealand University Libraries and Collaborative Storage.’ Library Management 34(4/5).

Robinson, Emma. 1999. "Repository Libraries-The University of London Experience and some Preliminary Indications for the Future of Collaborative Collection Management strategies in the University of London.” In Solving Collection Problems through Repository Strategies: Proceedings of an International Conference held in Kuopio, Finland, 9-11 May 1999: 83-88. Boston Spa: International Federation of Library Associations.

Seaman, Scott. 2005. "Collaborative Collection Management in a High-density Storage Facility.” College \& Research Libraries 66(1): 20-27.

Saarti, Jarmo. 2005. "From Printed Word to a Digital Environment: The Role of Repository Libraries in a Changing Environment.” Library Management 26(1/2): 26-31. 
Saarti, Jarmo, and Pentti Vattulainen. 2013 forthcoming. 'Management of and Access to Print Collections in National and Repository Libraries in Europe: Collection for Use or for Preservation.’ Library Management 34(4/5).

Sanz, Pascal. 1999. “The CTLES: A Repository for University Libraries in France.” In Solving Collection Problems through Repository Strategies: Proceedings of an International Conference held in Kuopio, Finland, 9-11 May 1999: 37-42. Boston Spa: International Federation of Library Associations.

Sharp, Steven. 2009. No More Room Aboard the Ark! A UK Higher Education Perspective on Space Management.” Interlending \& Document Supply 37(3): 126-131.

Shorley, Deborah. 2008. "Past its Shelve by Date? United Kingdom Research Reserve (UKRR): A Twenty-First-Century Strategy to Protect our Research Information for the Future.” New Review of Academic Librarianship 14(1): 115-120.

Simpson, Donald B. 1999. "How Repository Libraries Contribute Effectively to the Fabric of Collection Development and Management." In Solving Collection Problems through Repository Strategies: Proceedings of an International Conference held in Kuopio, Finland, 9-11 May 1999: 23-33. Boston Spa: International Federation of Library Associations.

Skold, Beatrice. 1999. "Is There a Need for Repository Libraries for the Blind and other Print Handicapped People." In Solving Collection Problems Through Repository Strategies: Proceedings of an International Conference held in Kuopio, Finland, 9-11 May 1999: 169176. Boston Spa: International Federation of Library Associations. Boston Spa: International Federation of Library Associations.

Vattulainen, Pentii. 2004. "National Print Repository Initiatives in Europe." Library Collections, Acquisitions \& Technical Services 28(1):39-50.

Vattulainen, Pentii. 2005. Access to Print Materials - Role of Print Repositories: The Development of the Concept.” Library Management 26(1/2): 42-48.

Weeks, David, and Ron Chepesiuk. 2002. "The Harvard Model and the Rise of Shared Storage Facilities.” Resource Sharing \& Information Networks 16(2): 159-168.

Wright, Janette, Cathie Jilovsky and Craig Anderson. 2012. "The Story of a Shared Last Copy Repository in Australia: The CARM Centre Stage 2 Development." Collection Management 37(3-4): 271-93.

Wright, Nicola, and Jean Crawford. 2008. Supporting Access to the UK's Research Collection: The UK Research Reserve Project.” Interlending \& Document Supply 36(4): 201212.

Yang, Daryl. 2013, forthcoming. "UK Research Reserve: A Sustainable Model from Print to E?” Library Management 34(4/5). 
Yoon, Hee-Yoon, and Sun-Kyung Oh. 2007. "Shortage of Storage Space in Korean Libraries: Solutions Centering upon Hub-based Collaborative Repositories.” Aslib Proceedings 60(3): 265-281. 